\title{
Plantando, colhendo, vendendo, mas não comendo: práti- cas alimentares e de trabalho associadas à obesidade em agricultores familiares do Bonfim, Petrópolis, RJ*
}

\author{
Growing, harvesting, selling, but not eating: food and work related \\ practices associated to obesity among family farmers in Bonfim, \\ Petrópolis, Rio de Janeiro, Brazil
}

\begin{abstract}
${ }^{1}$ Docente da Universidade Federal do Rio de Janeiro (UFRJ), Campus Macaé, RJ, Brasil.

* O presente trabalho é baseado na tese intitulada $O$ Bonfim na Balança: um estudo sobre ruralidade e saúde por meio da análise do estado nutricional, das práticas a limentares e da agricultura num bairro de Petrópolis, Rio de Janeiro, defendida pela autora na Escola Nacional de Saúde Pública da Fundação Oswaldo Cruz (ENSP/ Fiocruz), em 13 de agosto de 2010.

Durante a realização deste trabalho, a autora recebeu bolsa de doutorado do Conselho Nacional de Desenvolvimento Científico e Tecnológico (CNPq), processo $n^{\circ}$ 141256/2006-0, da Fundação de Amparo à Pesquisa do Estado do Rio de Janeiro (Faperj), processo $\mathrm{n}^{\circ}$ E-26/100.492/2008, e da Coordenação de Aperfeiçoamento de Pessoal de Nível Superior (Capes), processo n⿳ำ 4542/08-8.
\end{abstract}

Contato:

Ana Eliza Port Lourenço

Universidade Federal do Rio de Janeiro, Campus Macaé

Rua Aloísio da Silva Gomes, $\mathrm{n}^{\mathrm{0}} 50$ Granja dos Cavaleiros, Macaé-RJ

CEP: $27930-560$

Email:

ana.eliza@macae.ufrj.br

\section{Resumo}

Objetivo: verificar a prevalência de obesidade entre adultos das 86 famílias agricultoras de um bairro de Petrópolis, RJ, e analisar seus determinantes socioculturais. Métodos: estudo quantitativo e qualitativo sobre nutrição, práticas alimentares e de trabalho realizado em 2008. Dados antropométricos foram coletados por inquérito nutricional domiciliar e o material qualitativo por observação participante e entrevistas. Resultados: a prevalência de obesidade foi baixa $(9,3 \%)$ entre os homens, mas bastante elevada entre as mulheres (29,9\%). A prática agrícola local implica em atividade física leve para mulheres e intensa para homens. Essa diferença não é acompanhada na dieta, semelhante para homens e mulheres, com predomínio de alimentos de alto valor calórico. A produção familiar objetiva essencialmente a venda. A agricultura mercantil e a decorrente especialização dos cultivos favorecem comprar alimentos no mercado em vez de produzir para autoconsumo. Conclusão: os aspectos socioculturais e ocupacionais estudados podem ter contribuído para elevar a prevalência de obesidade nas mulheres e podem ser úteis no estudo de outros grupos com características semelhantes. Esta pesquisa ratifica a importância de estudar a obesidade em nível local, integrando abordagens quantitativas e qualitativas para identificar possíveis limitações e portas de entrada para ações de intervenção localmente relevantes.

Palavras-chave: estado nutricional; obesidade; hábitos alimentares; população rural; atividade física.

\begin{abstract}
Objective: To evaluate the prevalence of obesity and analyze its social-cultural determinants among adults from 86 farming families of a neighborhood of Petrópolis, in the mountain region of Rio de Janeiro state. Method: This quantitative and qualitative study on nutrition, food and work-related practices was conducted in 2008. The anthropometric data were collected by a household nutritional survey and the qualitative data, by participant observation and interviews. Results: The obesity prevalence among men was low (9.3\%) but it was very high (29.9\%) in women. Physical activity required for farm work in the region is more intense for men than for women. Despite this difference, men and women have similar diet that includes a high proportion of high calorie food items. Local families grow crops mainly for sale. Commercial agriculture with product specialization encourages purchasing rather than growing food for family consumption. Conclusion: The studied social-cultural and occupational aspects may have contributed to raise obesity among women in this community, and can be useful to study other populations with similar characteristics. This research confirms the significance of studying obesity at the local level, combining quantitative and qualitative approaches, in order to identify potential constrains and points of entry for locally relevant intervention programs.
\end{abstract}

Keywords: nutritional status; obesity; food habits; rural population; physical activity. 


\section{Introdução}

A obesidade é considerada questão prioritária na agenda mundial de saúde pública atual e acomete tanto países desenvolvidos, quanto aqueles em desenvolvimento, podendo apresentar prevalências variadas de acordo com diferentes regióes, estratos socioeconômicos e sexo (INTERNATIONAL OBESITY TASKFORCE, 2012). A preocupação global em torno da obesidade dá-se devido às implicações do excesso de massa corporal sobre a morbidade e a mortalidade, principalmente no que tange ao risco aumentado para doenças crônicas não transmissíveis. Destaca-se que tais doenças, como diabetes tipo II, câncer e problemas cardiovasculares, são responsáveis por cerca de $60 \%$ da mortalidade e $47 \%$ da carga de doença em termos mundiais (WORLD HEALTH ORGANIZATION, 2002).

No Brasil, a elevação da prevalência de obesidade associa-se ao processo de transição epidemiológica e nutricional (POPKIN, 2001; BATISTA-FILHO; RISSIN, 2003). Em linhas gerais, vem ocorrendo aumento da frequência de obesidade em todas as regiões e estratos socioeconômicos do país, primordialmente entre indivíduos adultos (ANJOS, 2006; INSTITUTO BRASILEIRO DE GEOGRAFIA E ESTATÍSTICA, 2010a). São escassos os estudos nacionais acerca do perfil nutricional de grupos agricultores (COORDENAÇÃO GERAL DA POLÍTICA DE ALIMENTAÇAO E NUTRIÇÃO, 2004). Estimativas recentes de âmbito nacional mostram incremento significativo do percentual de obesidade no meio rural brasileiro (INSTITUTO BRASILEIRO DE GEOGRAFIA E ESTATÍSTICA, 2010a). Essas estimativas podem representar parte das populações agricultoras do país, porém cabe ressaltar que não especificam que grupos rurais foram analisados (LOURENÇO, 2012).

Estudos, tanto nacionais, como internacionais, têm buscado diferentes abordagens explicativas em relação ao surgimento e à manutenção da obesidade (BOUCHARD, 1991; PEÑA; BACALLAO, 2000; SHELL, 2002; ANJOS, 2006; ULIJASZEK; LOFINK, 2006; POLLAN, 2008), porém, ainda não se sabe claramente porque diferentes subgrupos populacionais são acometidos de forma distinta. A literatura concorda que os dois aspectos mais fortemente relacionados ao acúmulo de gordura corporal consistem no consumo alimentar, com aumento do fornecimento de energia pela dieta, e na redução da atividade física. Por sua vez, alimentação e atividade física englobam múltiplas interações entre, por exemplo, a genética, o mercado global de alimentos, a mídia e o acesso aos transportes, construindo uma visão complexa a respeito dos determinantes da obesidade (SHELL, 2002; ULIJASZEK; LOFINK, 2006). Essa complexidade justifica pesquisas relativas ao tema, exigindo que perspectivas epidemiológicas e socioantropológicas se integrem de maneira a permitir maior compreensão dos contextos locais e favorecer intervenções efetivas (MINAYO et al., 2003; TROSTLE, 2005).

No que se refere a grupos agricultores no Brasil, pesquisas acerca da obesidade são particularmente relevantes, pois esses grupos apresentam uma história de discriminação e resistência face ao desenvolvimento da economia capitalista, marcada por intensas modificações sociais e ambientais desde a transição da economia agrária para a industrial (MOURA, 1988; NAVARRO, 2001). Tais mudanças estruturais repercutem sobre os determinantes do perfil de saúde e nutrição das populações, especialmente no tocante às alterações nos padrões de subsistência, ingestão alimentar e trabalho, podendo gerar um quadro de acentuada vulnerabilidade.

As famílias agricultoras do bairro Bonfim, em Petrópolis, RJ, inserem-se nesse contexto de vulnerabilidade. De acordo com os critérios do censo demográfico brasileiro (INSTITUTO BRASILEIRO DE GEOGRAFIA E ESTATÍSTICA, 2003), o Bonfim é considerado uma área urbana, sem especificações particulares. Entretanto, como observado por Paulino (2005), no interior desse espaço urbano, coexistem diferentes modos de ocupação aparentemente contraditórios, tais como região de agricultura familiar, periferia urbana e região de reserva florestal adjacente ao Parque Nacional da Serra dos Órgãos. Segundo esse autor, o Bonfim divide-se em distintas regiões socioespaciais. A agricultura familiar é predominante no "alto Bonfim", onde também residem empregados do ecoturismo e citadinos que optaram por morar no campo. Nas outras regiões do bairro, que compõem o "baixo Bonfim", predomina área residencial, com crescimento frequentemente desordenado, e não existem lavouras agrícolas. O bairro constitui um espaço em constante fluxo de distintos atores sociais inseridos em um processo histórico extremamente dinâmico, o qual inclui a decadência de uma antiga fazenda, a luta dos agricultores por sua sobrevivência econômica, a disputa com o Parque Nacional por justa delimitação e legalização da terra, a chegada de novos moradores estranhos ao local e a consequente expansão urbana. Essas características singulares são importantes, pois, como será visto no decorrer deste artigo, podem influir no perfil nutricional da população.

O objetivo deste estudo foi verificar a prevalência de obesidade entre os adultos das famílias agricultoras do Bonfim e avaliar os determinantes socioculturais desse problema nutricional nes- 
sa população. Analisa-se a intricada relação entre o que se planta, o que se vende e o que se come na localidade. Comenta-se a respeito das práticas alimentares e da atividade física das famílias, em especial sobre o trabalho - entendido aqui como o trabalho na lavoura ou em atividades a este relacionadas, tais como preparo de hortaliças para venda ou conserto de ferramentas.

\section{Métodos}

O presente estudo insere-se no contexto de uma pesquisa maior, de caráter quantitativo e qualitativo em nutrição e saúde, coordenada por esta autora, de abril a dezembro de 2008, no bairro Bonfim, localizado no município de Petrópolis, região serrana do estado do Rio de Janeiro (LOURENÇO, 2010). Essa pesquisa, chamada "Bonfim na Balança", incluiu a realização de um inquérito nutricional tipo censo, de base domiciliar, abrangendo toda a população residente no bairro. Por meio desse censo, foram coletadas informações antropométricas e de alimentação e saúde de 523 famílias (1.615 pessoas). O "Bonfim na Balança” incluiu ainda uma pesquisa etnográfica sobre nutrição, práticas alimentares e de atividade física, sendo feita observação participante e entrevistas com atores-chave.

O presente estudo descreve o perfil nutricional e analisa o material etnográfico referente às 86 fa- mílias agricultoras identificadas no bairro. Foram consideradas agricultoras as famílias cuja renda principal era oriunda da agricultura (Tabela 1).

Trata-se de um estudo com interação de métodos, sendo que a análise dos dados combinou resultados do inquérito com informações qualitativas, de forma a gerar discussões pertinentes e complementares. Resultados do inquérito indicando elevada prevalência de obesidade entre os adultos do Bonfim motivaram as análises em profundidade; e o material etnográfico, por sua vez, favoreceu a inferência de explicações acerca de tais resultados. A vivência durante os meses de visita às famílias no decorrer do inquérito fortaleceu o vínculo da pesquisadora com a comunidade e amadureceu seu entendimento a respeito do Bonfim, de sua gente e de suas questões sociais, sendo essencial para a análise do material qualitativo. As informações quantitativas nortearam a seleção dos informantes-chave e a realização das entrevistas.

\section{Métodos quantitativos}

Para fins de coleta de dados, duplas de pesquisadores previamente treinados visitaram os domicílios das 86 famílias agricultoras do Bonfim. Foram registradas em formulário específico informações sobre práticas alimentares e saúde das famílias.

Tabela 1 Famílias cuja renda principal advém da agricultura segundo o tipo de vínculo que o chefe da família tem com a produção agrícola, Bonfim, Petrópolis, RJ, 2008

\begin{tabular}{lc}
\hline \multicolumn{1}{c}{ Tipo de vínculo com a agricultura } & Total de famílias \\
\hline Agricultor/produtor rural & $44^{*}$ \\
Agricultor assalariado & 29 \\
Agricultor produtor aposentado & 5 \\
Agricultor assalariado aposentado & 5 \\
Cargueiro de caminhão**** & 3 \\
\hline Total de famílias & 86 \\
\hline * Quatro famílias declararam-se parceiras e não donas da terra. \\
**** Profissional contratado para auxiliar na colheita e colocar a produção nos caminhões de \\
transporte
\end{tabular}


A massa corporal dos adultos (idade igual ou superior a 20 anos) foi aferida uma vez, em quilogramas (kg), utilizando balança previamente calibrada, tipo digital portátil, marca Soehnle (Murrhardt, Germany), com capacidade máxima de 150 kg e precisão de 100 g. A medição da estatura deu-se duas vezes consecutivas por meio de estadiômetro portátil, marca Seca (Hamburg, Germany), com precisão de $1 \mathrm{~mm}$. A média aritmética entre as duas aferições forneceu o valor da estatura. As medidas foram realizadas com os indivíduos descalços e usando roupas leves. A avaliação do estado nutricional foi feita pelo índice de massa corporal (IMC). O ponto de corte para determinar obesidade foi IMC $\geq 30,0 \mathrm{~kg} \cdot \mathrm{m}^{-2}$ (WORLD HEALTH ORGANIZATION, 1995).

Foi calculada a frequência das categorias de estado nutricional segundo sexo e de outras variáveis coletadas no inquérito que interagem diretamente com a discussão qualitativa apresentada neste estudo.

\section{Métodos qualitativos}

Foram utilizadas técnicas de abordagem qualitativa para coletar informações detalhadas a respeito das experiências de vida das famílias agricultoras e de suas percepções acerca de aspectos relacionados com práticas alimentares, de atividade física e de agricultura. A pesquisadora viveu na comunidade durante os nove meses de atividade de campo, buscando participar de reuniões políticas e de socialização, conhecer o cotidiano local e interagir com os sujeitos pesquisados por meio do método antropológico da etnografia (CARDOSO-OLIVEIRA, 2000; ITURRA, 1986). Em linhas gerais, nesse método, o pesquisador busca entender a realidade pesquisada conforme observa, ouve e registra informações relevantes segundo um referencial teórico preestabelecido. Foi utilizado o recurso da observação participante e de entrevistas semiestruturadas com atores-chave. Um caderno de campo foi usado para registro de informações.

As entrevistas seguiram um roteiro específico, previamente testado. Procurou-se associar a história de vida das pessoas e suas percepções e representações em relação a dois eixos principais: (1) alimentação e ganho de peso e (2) trabalho e prática de atividade física. A pesquisadora selecionou para a entrevista pessoas-chave que, por sua posição social, ação ou responsabilidades, foram percebidas como capazes de fornecer informações relevantes acerca do universo da população pesquisada. Foram identificados 24 depoentes, incluindo homens e mulheres, com e sem excesso de peso, residentes em diferentes regiões do bairro, privilegiando indivíduos antigos na comunidade. Cabe dizer que se buscou compor um conjunto de depoentes socialmente representativo, não sendo o objetivo formar uma amostra es- tatística de entrevistados. Quando as 24 entrevistas estavam para ser concluídas, já não mais se percebia o acréscimo de novas informações relevantes e, por conseguinte, a seleção de informantes foi encerrada.

As entrevistas foram gravadas e transcritas por um profissional. Por meio de análise temática (BARDIN, 1995), a pesquisadora fez leitura flutuante das entrevistas e dos cadernos de campo de forma a impregnar-se com o material de estudo. Posteriormente, o material etnográfico foi explorado em profundidade e as falas dos informantes organizadas em categorias. As categorias foram interpretadas com base no cenário teórico delineado a priori e nos resultados do inquérito nutricional.

A pesquisa teve aprovação do Comitê de Ética em Pesquisa da Escola Nacional de Saúde Pública Sérgio Arouca, Fundação Oswaldo Cruz (Protocolo 42/08, no 0060.0.031.000-08).

\section{Resultados e discussão}

\section{Obesidade no Bonfim}

Foi avaliado o estado nutricional dos 173 adultos (50,3\% mulheres) que compõem as famílias agricultoras do Bonfim (Tabela 2). A prevalência de obesidade foi de $9,3 \%$ e $29,9 \%$ respectivamente para homens e mulheres. Os homens apresentaram cerca da metade da prevalência de obesidade dos não agricultores do bairro $(17,7 \%)$ (LOURENÇO, 2010). A obesidade entre os agricultores foi consideravelmente mais baixa que as estimativas nacionais, as quais, segundo o Instituto Brasileiro de Geografia e Estatística (2010a), são de 12,4\% para homens do Sudeste rural e 13,1\% para aqueles do Sudeste urbano.

A prevalência de obesidade entre as mulheres das famílias agricultoras foi semelhante àquela observada para outras mulheres do Bonfim (29,6\%) (LOURENÇO, 2010). A obesidade entre as agricultoras foi maior que as estimativas nacionais tanto para mulheres do Sudeste rural $(18,4 \%)$, quanto para aquelas do Sudeste urbano $(17,4 \%)$ (INSTITUTO BRASILEIRO DE GEOGRAFIA E ESTATÍSTICA, 2010a). Num estudo de base populacional com comunidades agrícolas do semiárido do Vale do Jequitinhonha, MG, a prevalência de obesidade foi menor que no Bonfim, porém igualmente mais acentuada em mulheres $(11,2 \%)$ que em homens (1,7\%) (VELÁSQUEZ-MELÉNDEZ et al., 2007).

Esses resultados suscitaram questionar que aspectos do Bonfim poderiam sugerir possíveis explicações para a obesidade observada. Por que apenas os homens agricultores apresentaram menor prevalência de obesidade que seus pares não agricultores 
Tabela 2 Estado nutricional segundo sexo de adultos cuja renda familiar principal advenha da agricultura, Bonfim, Petrópolis, RJ, 2008

\begin{tabular}{lccc}
\hline \multicolumn{1}{c}{$\begin{array}{c}\text { Classificação do índice de massa corporal } \\
\left(\mathrm{kg} . \mathrm{m}^{-2}\right)\end{array}$} & Masculino (\%) & Feminino (\%) & Total (\%) \\
\hline Obesidade $(\geq 30)$ & $8(9,3)$ & $26(29,9)$ & $34(19,7)$ \\
Sobrepeso $(25-29,9)$ & $29(33,7)$ & $26(29,9)$ & $55(31,8)$ \\
Adequado $(18,5-24,9)$ & $49(57,0)$ & $35(40,2)$ & $84(48,6)$ \\
\hline Total & $86(100)$ & $87(100)$ & $173(100)$ \\
\hline
\end{tabular}

e não também as mulheres? Tais questionamentos nortearam as análises apresentadas a seguir.

\section{Os "quatro cantos” do Bonfim: a prática agrícola local}

O Bonfim, segundo registros da associação local de produtores e moradores (ASSOCIAÇÃ̃O DE PRODUTORES E MORADORES DO BONFIM et al., 2009), passou a ser uma região agrícola somente na década de 1950, quando os proprietários da fazenda Bonfim faliram e seus funcionários passaram a habitar a região e a cultivar flores e hortaliças para autoconsumo e venda. As famílias passaram a utilizar para cultivo os pequenos espaços de terra entre os vales formados pelo relevo acidentado da localidade.

As mudanças ocorridas na prática agrícola no Bonfim inserem-se no contexto da evolução da atividade agrícola na região serrana do estado do Rio de Janeiro (CARNEIRO, 1998). Quando o Bonfim passou a ser uma área agrícola, o cultivo do café já estava sendo erradicado na região serrana e crescia o mercado da horticultura. Principalmente após 1970, a olericultura - cultivo de legumes e verduras cujo ano agrícola acompanha o ano civil, exigindo dedicação permanente de trabalho - tornou-se predominante na região serrana a fim de abastecer a área metropolitana do Rio de Janeiro, que estava em fase de rápido crescimento. Nessa mesma época, ocorreu a Revolução Verde na região, ou seja, a incorporação, na prática agrícola, de conhecimentos técnico-científicos acerca do cultivo de hortaliças com elevada produtividade, tendo frequentemente a mecanização e/ou a quimificação da agricultura como base (NAVARRO, 2001).

Com base nos relatos de atores da comunidade, foi possível entender que, no decorrer dos anos, houve aumento das relações dos agricultores do Bonfim com o mercado e a elevação gradativa da dependência da agricultura local para com produtos industrializados. Passou a existir maior dificuldade econômica, pois o uso de agrotóxicos por um lado eleva a produtividade da lavoura, mas, por outro, aumenta os gastos com insumos conforme promove um desequilíbrio ecológico devi- do a fatores diversos, tais como desgaste do solo, desmatamento e pouca diversificação de cultivos (PERES; ROZEMBERG; LUCCA, 2005). O desequilíbrio ecológico pode ser especialmente acentuado em propriedades de pequeno porte, como é o caso do Bonfim, onde as lavouras variam de um hectare (equivalente a $10.000 \mathrm{~m}^{2}$ ) até no máximo 15 hectares (ASSOCIAÇÃO DE PRODUTORES E MORADORES DO BONFIM et al., 2009).

O material etnográfico deste estudo permitiu concluir também que algumas famílias do Bonfim abandonaram o trabalho na lavoura e venderam suas terras, enquanto outras realizaram mudanças na prática agrícola com o objetivo de maximizar a produção para a venda e se manterem economicamente. O conjunto dessas modificações é chamado aqui de intensificação da agricultura, processo que influenciou sobremaneira o padrão de subsistência e de trabalho das famílias locais.

Devido ao relevo acidentado, a agricultura no Bonfim não pôde ser mecanizada. Este estudo identificou que aumentar a carga horária e a intensidade física do trabalho na lavoura foi uma alternativa para aumentar a produção. Embora alguns produtores tenham contratado funcionários ou estabelecido relações de parceria agrícola, a maioria dos agricultores teve que começar a trabalhar mais para produzir mais e ser competitivo no mercado.

Identificou-se ainda que a utilização de agrotóxicos cada vez mais intensa também foi uma saída para os produtores do Bonfim elevarem sua produção. O uso abundante de agrotóxicos tem sido observado em outras localidades da região serrana do Rio de Janeiro (PERES; MOREIRA, 2007), bem como em áreas agrícolas de outros estados brasileiros (FARIA et al., 2000; SOARES; ALMEIDA; MORO, 2003). Foi observado que no Bonfim ocorreu praticamente o abandono do "pousio", técnica de plantio baseada no repouso temporário das terras para recuperação da fertilidade. Os agricultores passaram a plantar e a colher diariamente, frequentemente em sistema de rodízio, alternando as hortaliças para tentar preservar o solo. 
Os agricultores do Bonfim organizaram-se em associação de produtores em 1984 (ASSOCIAÇÃO DE PRODUTORES E MORADORES DO BONFIM et al., 2009). A partir dessa data, especializar os cultivos passou a ser outra opção para tentar aumentar a renda familiar. Esta pesquisa observou que, em vez de plantar uma variedade de produtos, cada família passou a plantar um ou dois tipos de hortaliça, visando evitar competição dentro do bairro e, por conseguinte, encontrar uma melhor posição no mercado de vendas. Devido ao menor custo de produção, mais recentemente, a maioria dos agricultores do Bonfim preferiu cultivar folhagens. Couve, alface, salsa, cebolinha, brócolis, mostarda, chicória e hortelã são as principais culturas locais na atualidade, e a agricultura para autoconsumo tornou-se rara nas lavouras do bairro.

Quando questionado sobre quais eram as principais dificuldades relacionadas com o trabalho agrícola no Bonfim, um agricultor de 39 anos, fortemente ativo na associação de produtores local, disse: "O Bonfim aqui na parte de cima, tem quatro canto; as pessoas se dão bem, mas tem essa divisão, sabe?". Esta pesquisa observou que um dos "cantos" é onde esse agricultor vive: uma região bastante íngreme, de difícil acesso, especialmente na época de chuva. Algumas famílias desse canto passaram a combinar a produção de hortaliças com artesanato e produção de doces caseiros, visando aumentar a renda familiar. Outro canto fica próximo à entrada do Parque Nacional, onde grande parte das famílias passou a cultivar somente flores e, consequentemente, não disputam mercado com os produtores de hortaliças. No terceiro canto, há uma lavoura familiar de porte relativamente maior, que emprega pessoas de outras famílias do bairro, principalmente esposas de agricultores e filhos adolescentes. Devido à sempre delicada relação patrão-empregado e à competição pelo mercado de vendas, o relacionamento dos produtores desse canto com os outros produtores do Bonfim é, como resumiu o agricultor, "complicado".

A respeito do quarto canto, o agricultor comentou que "é o pessoal ali de baixo, das casas grandes, sabe? Lá da cooperativa”. O que o agricultor chamou de cooperativa é, na verdade, negócio de uma única família estendida que conseguiu tornar-se mais forte no mercado, construir casas percebidas pelo agricultor como "mansõeszinhas" e comprar caminhões, criando um sistema de transporte para vender a produção em locais mais distantes. Os agricultores dessa família têm suas próprias lavouras, mas também compram e revendem a produção de pequenos agricultores do bairro. Os agricultores desse canto também são, portanto, atravessadores, pois a cooperativa é atualmente o maior comprador da produção dos agricultores menores do Bonfim, sendo responsável por determinar a especialização dos cultivos e fazer a intermediação da venda com supermercados. Segundo o conjunto das observações de campo e falas de entrevistados, é possível concluir que a relação entre o quarto canto e os outros três é bastante complexa, pois há conflitos de interesse, e a falta de acordo acerca do preço pago pela produção local é constante.

Os "quatro cantos" do Bonfim ressaltam a diferenciação socioeconômica que ocorreu na comunidade devido aos distintos resultados que o engajamento na agricultura mercantil gerou para cada família. Observa-se também a intricada rede de escoamento da produção no bairro, mostrando as diferentes alternativas criadas para a sobrevivência no sistema econômico local. Como se pode ver pela contabilidade de uma família de pequeno porte, formada por um casal e dois filhos adolescentes (Tabela 3), são muitas as despesas na lavoura, principalmente com adubos e aditivos químicos. Entre despesas e lucros de venda, um dos agricultores comentou que "não sobra grandes coisas não [...], esse ano vai ser trocar seis por meia dúzia”.

Há variação no preço pago pelas hortaliças. Uma agricultora de pequeno porte esclareceu que isso ocorre porque o trabalho na lavoura é incerto, dependendo constantemente do clima. Por exemplo, no verão no Bonfim, devido às chuvas intensas, o cultivo de verduras é frequentemente dificultado, pois, como explica a agricultora, "a terra vira lama e [...] mela as folhas". Tal fato diminui a oferta e acaba elevando o preço local de venda. Complementa a agricultora: "a chuva prejudica a plantação e na época boa de venda você também não tem o produto. Tem uma coisa que fica meio desequilibrada".

Há cerca de dez anos, comentou um dos agricultores, o preço do "saco de adubo [de $50 \mathrm{~kg}$ ] era $\mathrm{R} \$ 12,00$, hoje tá R\$ 80,00”, e o preço de venda das hortaliças não acompanhou o aumento no custo das despesas. Tal situação faz com que grande parte dos agricultores do Bonfim, menores ou maiores, precisem trabalhar mais intensamente, plantando, colhendo e entregando mercadoria todos os dias, sob constante pressão para sustentar suas famílias. A intensificação da agricultura e o consequente aumento no tempo gasto com o trabalho são evidentes em toda a comunidade, como se pode perceber pelas falas de um grande produtor e de uma pequena produtora:

\begin{abstract}
Antes a gente trabalhava menos e ganhava mais; hoje é o contrário [...], a gente tem que arrancar muita alface pra comprar um saquinho de fertilizante. (grande produtor de 45 anos, pertencente ao quarto canto)

Naquela época tu tinha os dias de tu plantar e os dias de tu colher. E os dias de sair [...]; [hoje] é todo dia a mesma coisa, preocupação daqui e dali e vai embora. Não tem sol, não tem chuva, não tem nada... tem que encarar. (pequena produtora de 33 anos, pertencente ao terceiro canto)
\end{abstract}

Como será comentado adiante, tal aumento no tempo gasto com a produção para a venda resultou, em parte, na eliminação do tempo dedicado à produção para consumo familiar e, consequentemente, na redução do hábito das famílias de consumir o que produzem. 
Tabela 3 Exemplo de contabilidade mensal média de uma família (casal e dois filhos) produtora rural de pequeno porte no Bonfim, Petrópolis, RJ, março de 2010

\begin{tabular}{llc}
\hline \multicolumn{1}{c}{ Movimento financeiro } & \multicolumn{1}{c}{ Especificação } & Valor (Reais) \\
\hline Valores recebidos com a lavoura & Venda de hortaliças & $5.000,00$ \\
Gastos diretos com a lavoura & Esterco de galinha & $1.000,00$ \\
& Mudas & 900,00 \\
& Dois empregados & 900,00 \\
& Agrotóxicos & 300,00 \\
& Adubo químico & 200,00 \\
Subtotal - gastos com lavoura & Gasolina & 200,00 \\
Gastos domésticos & Fitilho (embalagem) & 50,00 \\
& & $3.550,00$ \\
Subtotal - gastos domésticos & Luz & 70,00 \\
Total de gastos fixos & Telefone & 55,00 \\
(lavoura + domésticos) & Supermercado (bruto) & 40,00 \\
Balanço final financeiro & & 450,00 \\
(recebido - gastos) & & 615,00 \\
\hline
\end{tabular}

档N Não inclui gastos semanais como açougue e padaria.

Plantando, colhendo e vendendo, mas não comendo: produção local e consumo de alimentos

Na percepção das pessoas cuja vida diária não envolve agricultura, trabalhar nas lavouras sugere uma dieta saudável com elevado consumo de frutas e hortaliças. No entanto, esse não é necessariamente o caso, pois há vários aspectos que podem interferir nos hábitos alimentares, tais como renda, educação e influência da mídia (GARCIA, 1997; MINTZ, 2001; CONTRERAS, 2005). Há ainda alguns aspectos do trabalho agrícola que podem vir a reduzir o consumo de frutas e hortaliças.

O que a gente mais planta aqui é brócole. Mas não me pergunta quantas vezes por mês tem brócole aqui em casa[...]. (agricultor de médio porte)

É muito difícil, quase nunca, a gente fica enjoado de ver o dia inteiro, que não aguenta comer. (esposa do agricultor)

As falas desse agricultor e de sua esposa exemplificam como o trabalho na agricultura pode vir a desestimular o consumo de hortaliças. Ficar "enjoado" de ver hortaliças por causa da rotina repetitiva do trabalho agrícola foi mencionado várias vezes nas conversas com os agricultores do Bonfim. Ter somente um ou dois tipos de verdura ou tempero na horta foi outra explicação frequente para não comer o que é plantado. A especialização do cultivo desmotiva o consumo de hortaliças locais, estimulando as famílias a comprarem produtos mais variados no mercado.
Trocar alimentos entre as famílias poderia ser uma alternativa para reduzir a monotonia das hortaliças disponíveis. Porém, trocar alimentos envolve relações vicinais de sociabilidade que, apesar de serem tradicionais em contextos rurais (BRANDÃO, 1981; CANDIDO, 1997), parecem estar estremecidas no Bonfim, devido à inserção das famílias na agricultura mercantil e à consequente diferenciação socioeconômica. Pessoas que pertencem à mesma família estendida, como irmãos e primos próximos, costumam trocar hortaliças. "A gente pega um do outro; só a gente que é da família", comentou uma das agricultoras entrevistadas. No entanto, dependendo do relacionamento familiar e das hortaliças disponíveis para troca, comprar do mercado é tido como mais simples. Por exemplo, um agricultor que produza somente alguns temperos ou flores não pode trocar por outras hortaliças regularmente.

Doações de alimentos também não são comuns no Bonfim. Uma das entrevistadas explica: "vai pegar uma vez, depois pega a segunda, na terceira tu já fica sem graça de ir buscar”. Mercantilizar a troca de hortaliças, comprando um dos outros, é aceitável na comunidade, especialmente quando a negociação é entre parentes, como o caso de uma família que cultiva apenas flores e semanalmente compra uma cesta com hortaliças da horta dos primos vizinhos. Mas tal relação de compra e venda não é comum no bairro como um todo, pois experiências anteriores com negociações que não deram certo desencorajam 
interações financeiras percebidas como desnecessárias. A fim de facilitar o escoamento da produção, os agricultores veem a necessidade de cooperarem uns com os outros; para ter alimento em casa, porém, comprar dos mercados é visto como mais prático.

Petrópolis tem vivenciado amplo crescimento nas últimas décadas (INSTITUTO BRASILEIRO DE GEOGRAFIA E ESTATÍSTICA, 2012), favorecendo a aproximação de contextos rurais com centros urbanos. Atualmente, há dois mercados a aproximadamente sete quilômetros do Bonfim. A partir de 2001, com a ampliação da linha de ônibus público por toda extensão do bairro, o acesso a esses mercados passou a ser relativamente fácil para todos os moradores. Apesar de serem mercados pequenos, vendem uma variedade de produtos vindos de localidades diversas. Há ainda uma padaria e um mercadinho no baixo Bonfim que fazem o papel de "loja de conveniência”, vendendo diversos produtos industrializados, tais como biscoitos, enlatados, refrigerantes e sorvetes. O mercadinho também vende banana, tomate, batata e cebola, oriundos de mercados fora do bairro.

Em paralelo às vendas, os agricultores poderiam plantar algumas hortaliças para consumo próprio, mas uma das agricultoras esclarece:

[...] perdemos o hábito de fazer as pequenas plantações. [...] Tu ocupa muito espaço com as outras plantações, então, com aquelas pequenas coisas que você poderia ter até na beirada do canteiro, você não liga de plantar.

Em outras regiões agrícolas brasileiras, como o caso do Vale do Taquari no Rio Grande do Sul (MENASCHE; SCHMITZ, 2007; WAGNER; MARQUES; MENASCHE, 2007), o cultivo de hortaliças variadas para autoconsumo é mais presente na atualidade devido, sobretudo, ao contexto histórico de formação das comunidades e às especificidades da mercantilização da agricultura local. No Bonfim, plantar para autoconsumo é percebido como algo que não vale a pena, como trabalho extra, perda de tempo e de espaço na horta, especialmente se comparado com a conveniência e os preços relativamente baratos dos alimentos nos mercados.

A noção contemporânea de que alimentos orgânicos são mais saudáveis que os convencionais poderia justificar plantar para autoconsumo. Essa noção foi observada em populações agrícolas nos estados do Rio Grande do Sul (WAGNER; MARQUES; MENASCHE, 2007), Paraná (RIGON et al., 2006), São Paulo (SAMPAIO et al., 2006) e também no Rio de Janeiro, no município de Nova Friburgo (CARNEIRO, 2009). Nessas populações, alimento "sem agrotóxico" associa-se à percepção de alimento saudável, e os autores relataram que algumas famílias mantêm, em separado da lavoura comercial, uma "hortinha” orgânica para auto- consumo. Porém, no Bonfim, as entrevistas não mostraram a percepção de que alimento sem agrotóxico é mais saudável ou de que alimentos convencionais podem não ser apropriados para consumo. A utilização inadequada do agrotóxico ou "veneno" é percebida como prejudicial ao alimento e à saúde das pessoas, mas o agrotóxico ou "remédio" é visto como necessário para matar as pragas e seguro para a saúde se, explicou uma das agricultoras, "você souber como e quando usar, respeitando os dias de carência”.

Os alimentos orgânicos parecem ser vistos no Bonfim como "coisa pra gente rica”, "bonitinhos" (expressões citadas em entrevista), mas desvantajosos para o produtor. O nicho de mercado de orgânicos começou a crescer no Brasil somente no fim da década de 1990 e tem enfrentado vários entraves de comercialização, tal como o elevado preço dos orgânicos em comparação aos produtos convencionais (CAMPANHOLA; VALARINI, 2001; ORMOND et al., 2002; FONSECA et al., 2009). Por conseguinte, os agricultores do Bonfim consideram arriscado mudar a forma de cultivar que têm utilizado por vários anos. Na visão da maioria dos agricultores da comunidade, não é possível ser competitivo no mercado e sustentar a família por meio da agricultura orgânica, porque, como falou a esposa de um agricultor de pequeno porte, "se a gente não põe veneno, a planta não sai da terra! [...] Senão vai tirar dinheiro de onde?”.

O estigma de que rural é "atrasado" e a situação de exclusão social que acomete o Bonfim, principalmente acerca do insucesso após décadas de luta das famílias para resolver a questão fundiária com o Parque Nacional (ASSOCIAÇÃO DE PRODUTORES E MORADORES DO BONFIM et al., 2009), poderiam ser fatores que, por oprimirem a população, estimulassem a valorização de produtos e hábitos oriundos "de fora" da comunidade, tal como a preferência por alimentos industrializados em detrimento de produtos locais. No entanto, essa hipótese não se confirmou nas entrevistas. As famílias reconhecem que as hortaliças do mercado não são tão, como disse uma agricultora, "fresquinhas" quando comparadas com aquelas das suas hortas e podem ter sido cultivadas com manejo inadequado de agrotóxico. Essa percepção de que o alimento local é mais saudável por existir um controle da sua qualidade também foi observada em Nova Friburgo (CARNEIRO, 2009). Tal visão pode favorecer o consumo, entre as famílias, de alimentos por elas produzidos, mas, no Bonfim, os obstáculos gerados pelo sistema de produção parecem prevalecer sobre essa percepção, forçando a busca por maior variedade no mercado.

Cabe destacar a importante diferença entre "consumir o que se planta" e "plantar para o consumo". Em linhas gerais, as famílias agricultoras do Bonfim 
pouco consomem do que plantam, porque não produzem variedade, poucos trocam ou doam alimentos entre si e não há um esquema amplo entre as famílias para a compra de hortaliças locais para autoconsumo. Uma família que cultiva apenas cheiro-verde, por exemplo, consome este quando necessário em sua culinária. Porém, a família recorrerá ao mercado caso deseje hortaliças variadas. As famílias não plantam para o consumo, pois a produção objetiva a venda e, na balança da praticidade, a fim de ter mais tempo para produzir e vender, as famílias poupam tempo comprando alimentos do mercado.

Como será comentado a seguir, diferentes percepções acerca do alimento vão orientar a escolha dos produtos no momento da compra no mercado, de forma que não consumir hortaliças também pode ser uma prática das famílias.

\section{Feijão com arroz é a comida de todo brasileiro: práti-} cas alimentares locais

Seria aparentemente ótimo se bastasse ensinar à população "como se deve comer" para que as pessoas fizessem "escolhas alimentares certas" e grande parte dos problemas de saúde relacionados à obesidade fosse resolvida. Todavia, entender os determinantes que interferem nos hábitos alimentares e favorecem a obesidade permanece como desafio para a saúde global (WORLD HEALTH ORGANIZATION, 2000; BRESLOW, 2006), mesmo havendo ampla divulgação nas mídias públicas sobre alimentação saudável. Não se está afirmando aqui que todas as pessoas são especializadas nas ciências da nutrição, mas sim que princípios básicos suficientes para orientar hábitos alimentares saudáveis devem ser conhecidos pelas populações que têm serviço público de saúde e televisão em casa, como é o caso de $90 \%$ da população brasileira (INSTITUTO BRASILEIRO DE GEOGRAFIA E ESTATÍSTICA, 2007).

A maioria $(68,8 \%)$ dos adultos agricultores do Bonfim estudou somente até a quarta série do Ensino Fundamental (atual quinto ano). No entanto, quando questionados sobre alimentação saudável, eles sabiam claramente que: frutas e hortaliças fazem bem a saúde; "massa" e doces em excesso podem fazer você engordar; refrigerantes e hambúrgueres "com um monte de coisa dentro" não são bons para a saúde; fritura "engordura minhas artérias e meu fogão". Até mesmo orientações nutricionais mais específicas foram mencionadas nas entrevistas, tais como preferir pães integrais com "sementinhas", alimentar-se de acordo com a "pirâmide" e variar as quantidades de "vegetal A e vegetal B" na dieta. Esses resultados sugerem que outros aspectos além de simples conhecimento nutricional parecem interferir nos hábitos alimentares locais.
Existe, em parte, a percepção de que atualmente a vida cotidiana no Bonfim é melhor que no passado, com acesso mais fácil a alimentos variados. Porém, por outro lado, os entrevistados também demonstraram nostalgia referente à forma de plantar do passado, criar animais e comer, pois antigamente se plantava para o consumo familiar, havia maior variedade de hortaliças nas lavouras locais e "a plantação dava melhor e não precisava botar tanto remédio igual hoje". Além disso, "tinha sempre galinha em casa, poxa, que diferença da galinha comprada", e "a gente era acostumado a criar porco em casa e aquilo era saudável porque você tratava do animal [...], hoje em dia não, eles dão hormônio pro porco crescer" (agricultora nascida no bairro).

A alimentação no passado na região do Bonfim era baseada em feijão, milho e aipim, tendo hortaliças cozidas como complemento. Pratos como angu de milho e aipim cozido eram muito comuns na rotina diária, que mais tarde incorporou também arroz, pão e macarrão, bem como café. Tinha-se, portanto, uma dieta com alimentos de elevado valor calórico. A carne estava presente na alimentação quando havia criação doméstica de animais, de onde se tiravam também ovos e leite. Ter pomar em casa também era hábito das famílias, e as frutas complementavam a dieta na época da safra.

Muitos desses hábitos alimentares do passado permanecem vivos na comunidade. Alimentos de elevado teor energético permanecem predominantes na dieta, relacionados com a percepção de que a prática agrícola exige intenso desgaste físico. $\mathrm{Na}$ visão dos agricultores, sua ocupação requer comida que "sustenta" o corpo, tais como, arroz, feijão, pão, macarrão, batata e aipim. Esses alimentos são percebidos como essenciais, enquanto hortaliças e frutas são reconhecidas como importantes, mas como complemento da dieta. Arroz com feijão não pode faltar, pois, como comentado por um agricultor, "é a comida de quase todo brasileiro". A carne ou "mistura" também é vista como essencial, mas, por ser a parte mais custosa da alimentação, é percebida como luxo que, na rotina alimentar, pode ser substituída por embutidos ou ovos, ou então não existir, desde que o arroz e o feijão estejam presentes. Somente 27 famílias agricultoras $(31,4 \%)$ relataram criar algum animal para consumo, sendo galinha e porco os mais citados. Seis dessas famílias criam coelhos para venda e consumo em dias comemorativos. Logo, pode-se concluir que a carne do cotidiano é geralmente comprada do mercado.

Pomares com ao menos um tipo de árvore frutífera estão presentes nos quintais de $63,5 \%$ das famílias, sendo banana, laranja, abacate, caqui e jabuticaba as frutas mais citadas. As frutas geralmente não são vendidas, não havendo investimento nem de 
tempo, nem de dinheiro nos pomares. É importante dizer que a presença dos pomares não necessariamente implica o consumo de frutas. Das famílias que possuem pomar, 53,7\% relataram não consumir frutas habitualmente. Do total de famílias agricultoras, 49,4\% disseram habitualmente consumirem frutas em pelo menos uma refeição diária. Essas frutas são frequentemente adquiridas nos mercados.

Alimentos industrializados, tais como biscoito, iogurte, sucos artificiais e refrigerantes, foram também incorporados à alimentação habitual das famílias do Bonfim, principalmente após o aumento da relação dessas com os centros urbanos. Tal incorporação pode ter sido motivada pela inexistência, no passado, de infraestrutura para acessar esses produtos, incluindo energia elétrica, linha de ônibus e os próprios mercados da região. Na época que as famílias começaram a cultivar a terra no Bonfim, uma agricultora esclarece que a:

vida não era fácil $[. .$.$] eu era pequena [...] minha mãe$ largava cedo da horta pra cuidar de mim, tinha que esquentar a água e aquela coisa toda, não tinha luz, era tudo lampião e vela.

Uma ex-agricultora, moradora do bairro desde que nasceu, há 43 anos, destacou que tinha que comer o mesmo pão a semana inteira, pois "meu pai só ia pra cidade uma vez por semana e trazia pão”. Com entusiasmo, ela acrescentou que hoje "todo dia trago pão fresquinho”. Junto com o pão, são trazidos outros produtos que antes ou não existiam na comunidade, ou não faziam parte dos hábitos das famílias, ou não se tinha dinheiro para comprar.

Por exemplo, o consumo de refrigerantes é amplamente popular no Bonfim. Das famílias agricultoras, $44,7 \%$ relataram que habitualmente bebem refrigerante em pelo menos uma refeição diária. O percentual sobe para $68,2 \%$ considerando-se as famílias que habitualmente bebem refrigerante em pelo menos uma refeição nos finais de semana. Um dos agricultores comentou que o refrigerante:

[...] se tornou quase um vício. [...] A gente gosta, é bom. É difícil imaginar almoçando alguma coisa sem um refrigerante [...]. Só quando não tem mesmo é que vai água.

A esposa de outro agricultor ressaltou que o refrigerante:

[...] é também um pouco de comodidade, né? [...] Com pressa de almoçar eu não faço suco, eu tomo o que tiver lá, se tiver refrigerante... pronto, é o que eu tomo.

É importante acrescentar que os refrigerantes estão amplamente disponíveis na padaria, no mercadinho e nos bares do bairro, bem como nos supermercados próximos ao Bonfim por preços relativamente baixos quando comparados com o preço das frutas e dos sucos naturais.
O consumo de fast food fora de casa, como salgados, pizza e sanduíches, não é comum para as famílias agricultoras do Bonfim. Nos restaurantes e bares do centro comercial mais próximo do bairro, é possível encontrar esses alimentos. Porém, as famílias habitualmente realizam as refeições em casa ou levam marmita para a lavoura onde trabalham. Trocar a "janta" (entendida por arroz e feijão como base) por um "lanche" em casa (entendido por pão como base) é habitual somente para cinco famílias (5,9\%). Já o hábito de, no final de semana, comer pizza ou sanduíches em casa como substituição ao jantar foi relatado por 26 famílias (30,6\%).

A incorporação de produtos industrializados na alimentação no Bonfim parece seguir a tendência nacional de consumo observada pelas pesquisas de orçamentos familiares mais recentes, as quais indicam aumento da aquisição de refrigerantes e outros alimentos processados prontos para consumo, tais como biscoitos e pães (INSTITUTO BRASILEIRO DE GEOGRAFIA E ESTATÍSTICA, 2010b). No que se refere às diferenças na disponibilidade de alimentos segundo a situação rural ou urbana dos domicílios brasileiros, as pesquisas de âmbito nacional sugerem que, no meio rural, há menor gasto com alimentação fora de casa e maior participação na dieta de alimentos tradicionais da culinária brasileira, como arroz e feijão. Tais aspectos também são observados no Bonfim. Entretanto cabe lembrar que a comparação das observações sobre alimentação no Bonfim com dados nacionais para o meio rural deve ser feita com cautela, pois esses não são específicos para grupos de agricultores (LOURENÇO, 2012).

O café da manhã usual no Bonfim acontece por volta das seis horas e inclui café, açúcar branco, leite, pão branco (geralmente francês ou de forma), manteiga ou margarina, bolo caseiro (frequentemente de milho ou aipim), biscoitos variados e, para algumas famílias, fruta. Com exceção do bolo, todos os outros itens são habitualmente comprados nos mercados. Entre nove e dez horas, as famílias fazem o lanche da manhã, o qual é semelhante ao desjejum, podendo incluir também um alimento proteico no recheio do pão, como ovo ou presunto. $\mathrm{O}$ almoço, às doze horas, é tido como a principal refeição do dia, sendo um momento de descanso e, frequentemente, de reunião da família. $\mathrm{O}$ almoço usual inclui arroz branco, feijão preto, uma hortaliça cozida, carne bovina ou frango e mais raramente carne suína ou peixe. As carnes são preparadas de formas variadas, sendo carne de panela, bife frito, carne moída e frango ensopado os pratos mais citados nas entrevistas. Rabada e carne assada são preparações frequentes no final de semana. Sobremesas, tais como doces em compota e goiabada, também são frequentes na hora do almoço, assim como refrescos/sucos industriali- 
zados e refrigerantes. Às dezesseis horas acontece o lanche da tarde, semelhante ao desjejum. O jantar ocorre por volta das dezenove horas, sendo, na maioria das vezes, semelhante ao almoço. O hábito de cear não é comum, possivelmente devido ao costume da maioria das famílias de dormir cedo.

O Quadro 1 apresenta a alimentação habitual de três famílias produtoras com diferentes perfis de consumo alimentar. Essas famílias não são necessariamente representativas do universo de estudo, porém ilustram aspectos relevantes da alimentação local. Observa-se que os alimentos que "sustentam", como referidos pelos agricultores (arroz, feijão e pão), estão presentes em todas as refeições. A alimentação da Família 1 inclui um cardápio de baixo custo, que pode ser percebido pelo tipo da "mistura" (carne, salsicha e ovo). A Família 2 consome maior variedade de carne, biscoito diariamente e observa-se a presença da "misturinha", citada pela entrevistada como comum no lanche da manhã. A Família 3 consome refrigerante diariamente e, diferentemente das Famílias 1 e 2, consome frutas habitualmente e não tem o hábito de comer verduras. Tanto a Família 2 como a 3 costumam substituir o jantar por lanche nos finais de semana.

Quadro 1 Alimentação habitual de três famílias produtoras do Bonfim, Petrópolis, RJ, 2008

\begin{tabular}{|c|c|c|c|}
\hline \multirow{2}{*}{$\begin{array}{l}\text { Refeição } \\
\text { Horário }\end{array}$} & \multicolumn{3}{|c|}{ Alimentos habitualmente consumidos } \\
\hline & Família 1 & Família 2 & Família 3 \\
\hline $\begin{array}{l}\text { Desjejum } \\
\text { 05h30-06h30 }\end{array}$ & $\begin{array}{l}\text { Café, pão, margarina, bolo } \\
\text { caseiro. } \\
\text { Obs.: às vezes tem também } \\
\text { leite e mortadela. }\end{array}$ & $\begin{array}{l}\text { Café, leite, pão, manteiga, biscoito. } \\
\text { Obs.: no final de semana tem tam- } \\
\text { bém pão doce, queijo e presunto. }\end{array}$ & Café, leite, pão, biscoito. \\
\hline $\begin{array}{l}\text { Lanche } \\
\text { 09h-10h }\end{array}$ & $\begin{array}{l}\text { Café, pão, margarina, bolo } \\
\text { caseiro. }\end{array}$ & $\begin{array}{l}\text { Café, pão com ovo mexido ou com } \\
\text { mortadela. }\end{array}$ & Fruta, biscoito \\
\hline $\begin{array}{l}\text { Almoço } \\
12 \mathrm{~h}\end{array}$ & $\begin{array}{l}\text { Arroz, feijão, salsicha ou } \\
\text { carne moída ou ovo, verdura e } \\
\text { legume, comumente couve e } \\
\text { batata cozida, refresco indus- } \\
\text { trializado. } \\
\text { Obs.: no final de semana tem } \\
\text { também refrigerante }\end{array}$ & $\begin{array}{l}\text { Arroz, feijão, carne bovina ou fran- } \\
\text { go, verdura e legume, comumente } \\
\text { couve e batata cozida, refresco } \\
\text { industrializado. } \\
\text { Obs.: no final de semana costuma } \\
\text { ter uma massa, comumente nhoque } \\
\text { ou lasanha. }\end{array}$ & $\begin{array}{l}\text { Arroz, feijão, carne bovina ou } \\
\text { frango, legume, refrigerante ou } \\
\text { refresco industrializado. } \\
\text { Obs.: às vezes tem ovo ou salsi- } \\
\text { cha em vez de carne e frango. }\end{array}$ \\
\hline $\begin{array}{l}\text { Lanche } \\
\text { 16h-17h }\end{array}$ & $\begin{array}{l}\text { Café, pão, margarina, bolo } \\
\text { caseiro. }\end{array}$ & $\begin{array}{l}\text { Café, pão, manteiga, bolo, biscoito. } \\
\text { Obs.: no final de semana tem tam- } \\
\text { bém refrigerante. }\end{array}$ & $\begin{array}{l}\text { Café, leite, pão. } \\
\text { Obs.: no final de semana tem } \\
\text { também biscoito e fruta. }\end{array}$ \\
\hline $\begin{array}{l}\text { Jantar } \\
\text { 19h-20h }\end{array}$ & Idem ao almoço & $\begin{array}{l}\text { Idem ao almoço ou tem canja. } \\
\text { Obs.: no final de semana tem sem- } \\
\text { pre um doce e substituem o jantar } \\
\text { por empadão, ou cachorro-quente, } \\
\text { ou hambúrguer, ou pastel. }\end{array}$ & $\begin{array}{l}\text { Idem ao almoço. } \\
\text { Obs.: no final de semana subs- } \\
\text { tituem o jantar por bolo e pizza } \\
\text { ou misto quente. }\end{array}$ \\
\hline
\end{tabular}

Obs: Informações fornecidas pelo responsável por preparar as refeições da casa, no caso, as esposas. 
Tais características da dieta habitual, com predominância de alimentos energéticos e incorporação de alimentos industrializados, podem favorecer o acúmulo de gordura corporal. Ao descrever a alimentação que prepara para sua família, uma agricultora que trabalha com o cultivo de flores destacou que “o feijão e o arroz tem que ter sempre!" e que sempre prepara "um macarrão, uma batata, verdura e legume". Ela tem obesidade e tem tentado perder peso comendo "mais salada, legume e verdura", mas sem sucesso, porque:

[...] se a gente trabalhar o dia inteiro e comer só um pedacinho de carne e uma salada... A gente que trabalha assim tem que comer, tem que se alimentar que senão a gente não aguenta.

Outra agricultora, preocupada em perder peso, colocou a mão sobre sua barriga um pouco saliente e perguntou:

[...] mas o que vou fazer? Não tem mais o que tirar. Tirar o meu arroz com feijão também não dá! Mas se falar que tem que comer alface, a gente come, ué.

Essas falas associam perda de peso com o consumo de salada, percebida como vegetais, em sua maioria crus e com presença de folhas. Destaca-se que "salada" difere de "verdura e legume", os quais normalmente são cozidos ou refogados, como ocorre com couve, batata e aipim. Hortaliças cruas acompanhadas de uma carne compõem um cardápio comumente indicado para dietas de baixa-caloria, mas que não é habitual no Bonfim. Tal fato, juntamente com possível complexidade na obtenção de carnes, prejudica a aceitação desse cardápio na rotina alimentar local. Além disso, consumir maior quantidade de hortaliças e carne sem reduzir as porções de outros alimentos dificilmente vai contribuir para a perda de peso sem que ocorram mudanças também na atividade física.

\section{Meu trabalho é a minha atividade física: práticas locais de atividade física}

O processo de intensificação da agricultura passou a exigir um desgaste físico demasiado para algumas famílias ou, em sentido oposto, estimulou a contratação de lavradores, reduzindo a participação familiar no trabalho. O papel dos homens e das mulheres na organização do trabalho também sofreu influência das mudanças na prática agrícola, favorecendo marcantes diferenças no nível de atividade física entre os gêneros.

Minha caminhada era só na roça, né? Meu exercício todo era só na enxada. [...] Se você quer ficar musculoso, pega a enxada e puxa a enxada. (agricultora de pequeno porte de 33 anos)

Como demonstra a fala dessa agricultora, os entrevistados enfatizaram que sua atividade física tem sido essencialmente o trabalho. O hábito de praticar esportes ou outras atividades físicas voluntárias é praticamente inexistente para os agricultores familiares do Bonfim. As atividades religiosas constituem a única atividade rotineira de não trabalho entre as famílias, em especial no "dia de domingo". O Quadro 2 exemplifica a rotina de atividades de um agricultor e de uma agricultora. O trabalho ocupa muitas horas diárias de ambos, havendo importante diferença de gênero, uma vez que a mulher, além de trabalhar na lavoura, realiza atividades domésticas. O trabalho, por si só, é tido como muito cansativo, inviabilizando a prática de outras atividades. Porém, o termo "cansativo" refere-se tanto a intenso gasto energético, quanto a atividades repetitivas ou enjoativas, exigindo analisar com cautela as diferenças nas atividades praticadas por homens e mulheres.

As atividades tipicamente masculinas requerem intenso gasto energético, pois, como descreve um dos entrevistados, incluem:

molhar, por os produtos, plantar, colher, cavaquear com máquina [...]. A área é muito grande pra pouca gente que trabalha [...], você tá levando às vezes saco de adubo lá pra cima, carregando caixa de verdura, nunca tá andando à toa, mas tá andando e carregando peso [...]. Tem que ter bastante disposição.

O nível de atividade física dos homens pode ter sido ainda mais incrementado pela intensificação da agricultura.

Antigamente, as mulheres também faziam atividades pesadas na lavoura, além de cuidar da casa e dos filhos. Uma das agricultoras contou que seu marido "cavava, mas eu tinha que levantar a rua pra fazer os canteiros [...], eu tinha que esparramar o esterco e o esterco também era pesado”. Hoje, cuidar do lar permanece como atividade feminina, mas a maioria das mulheres das famílias agricultoras somente ajuda na lavoura (principalmente na colheita) e prepara hortaliças ou flores para venda. É importante comentar que, como as mulheres se percebem parte integrante da família agricultora, elas se autodenominam agricultoras/produtoras rurais, independentemente das mudanças ocorridas na produção agrícola.

O uso intensivo de agrotóxicos foi um dos aspectos que afastou as mulheres da lavoura, pois os produtos "têm um cheiro horrível [...] aquilo não é serviço pra mulher" (agricultora de pequeno porte). A atividade tipicamente feminina, como "amarrar cheiro" (cheiro-verde), é "cansativa” por ser repetitiva, porém não impõe gasto energético elevado:

Você fica em pé ou sentada várias horas na mesma posição, só amarrando. [...] Aí você enjoa porque fica aquele tempo parado ali, fechado. Quando sai dali já sai até... Nossa! Doida pra sair e arejar um pouco a cabeça. 
Quadro 2 Rotina diária habitual de um agricultor e de uma agricultora familiar do Bonfim, Petrópolis, RJ, 2008

\begin{tabular}{|c|c|c|}
\hline \multirow{2}{*}{ Horário } & \multicolumn{2}{|c|}{ Atividades habitualmente realizadas em um período de 24 horas } \\
\hline & Agricultor & Agricultora \\
\hline 06h & Dormindo & Acorda, toma café e arruma os filhos para o colégio \\
\hline $06 h 30$ & Acorda e leva a filha para escola de carro & Arruma a casa \\
\hline $07 \mathrm{~h}$ & Toma café & Arrumando a casa \\
\hline 07h30 & $\begin{array}{l}\text { Começa a trabalhar na lavoura (na sua própria } \\
\text { casa) }\end{array}$ & $\begin{array}{l}\text { Caminha } 5 \text { minutos até a lavoura de sua família e } \\
\text { começa a trabalhar }\end{array}$ \\
\hline $09 \mathrm{~h} 30$ & Entra em casa e lancha & Lancha \\
\hline $09 \mathrm{~h} 40$ & Volta a trabalhar & Volta a trabalhar \\
\hline $11 \mathrm{~h}$ & Trabalhando & Caminha 5 minutos até sua casa e prepara o almoço \\
\hline $12 \mathrm{~h}$ & Trabalhando & Serve o almoço para a família e almoça \\
\hline $12 \mathrm{~h} 30$ & Entra em casa e almoça & Caminha 5 minutos até a lavoura e volta a trabalhar \\
\hline $13 \mathrm{~h}$ & Volta a trabalhar & Trabalhando \\
\hline $16 \mathrm{~h}$ & Trabalhando & Lancha \\
\hline $17 \mathrm{~h}$ & Trabalhando & Caminha 5 minutos até sua casa e prepara o jantar \\
\hline $18 \mathrm{~h} 30$ & Entra em casa e lancha & Serve o jantar para a família e janta \\
\hline $19 \mathrm{~h}$ & Dirige caminhão para fazer entregas & Arruma a casa \\
\hline $21 \mathrm{~h}$ & Fazendo entregas & Senta e assiste televisão \\
\hline $22 \mathrm{~h} 30$ & Chega em casa e janta & Vai dormir \\
\hline $23 \mathrm{~h} 30$ & Vai dormir & Dormindo \\
\hline--- & $\begin{array}{l}\text { Obs.: Sábado é o dia de colheita até as } 18 \mathrm{~h} \text { e } \\
\text { nem sempre faz entrega à noite. Aos domingos } \\
\text { colhe pela manhã, à tarde faz entrega e à noite } \\
\text { descansa }\end{array}$ & $\begin{array}{l}\text { Obs.: Aos sábados não trabalha na lavoura, limpa } \\
\text { a casa e lava roupa. Aos domingos trabalha apenas } \\
\text { pela manhã, descansa à tarde. Às } 18 \mathrm{~h} \text { caminha até a } \\
\text { igreja ( } 10 \text { minutos ida e volta), onde fica por } 1 \text { hora }\end{array}$ \\
\hline
\end{tabular}

Obs: $\mathbf{O}$ agricultor $\mathrm{e}$ a agricultora pertencem a famílias distintas.

Algumas famílias são exceções, como a de um grande produtor, classificado com obesidade, que tem empregados lidando com sua terra, enquanto ele trabalha a maioria do tempo dirigindo caminhão de entrega de mercadoria. Há também uma esposa, classificada com peso adequado, que faz trabalho pesado na lavoura junto com o marido. Existem ainda famílias pluriativas, nas quais mulheres e/ou filhos exercem ocupação principal não agrícola (CARNEIRO; TEIXEIRA, 2004). Contudo, no padrão geral de organização do trabalho, os homens têm maior gasto energético que as mulheres, o que pode ser uma explicação para a menor prevalência de obesidade entre os homens do que entre as mulheres agricultoras do Bonfim.

Ressalta-se que o preparo da alimentação local segue a tradição campesina, sendo as refeições preparadas pela mulher para a família, privilegiando as preferências e necessidades masculinas. Logo, a dieta das mulheres tende a ter a mesma composição daquela de seus maridos. O trabalho na lavoura familiar como um todo é percebido como "cansativo" e, por isso, na visão dos agricultores, requer uma alimentação que "sustente" todos da família. Essa situação favorece que as mulheres tenham um balanço energético positivo, acentuando o risco para obesidade.

Algumas mulheres tentam fazer caminhadas a fim de emagrecer, mas comentam que tem sido complicado conciliar a caminhada com o cansaço e o tempo de dedicação exigido pelo trabalho na lavoura e no domicílio. Outros aspectos que dificultam a prática de atividade física no Bonfim são o terreno acidentado da região, a falta de iluminação pública em muitos trechos do bairro e a presença de cachorros soltos pela vizinhança. No alto Bonfim, há dois campos de futebol society, mas ambos são particulares e frequentados esporadicamente apenas por homens. Na região de baixo, há a quadra poliesportiva da Associação de Moradores, porém não há 
uma programação com atividades para mulheres, predominando somente futebol masculino. No alto Bonfim, há um centro para esportes de aventura e o Parque Nacional dispõe de trilhas e cachoeiras. No entanto, tais atividades são relativamente caras e geralmente praticadas de forma esporádica, predominantemente por jovens e turistas. No centro comercial próximo ao bairro, há uma academia de ginástica e um clube onde se pratica hóquei sobre patins. Entretanto, essas atividades requerem tempo, custo com transporte e mensalidade, além de não fazerem parte dos hábitos dos agricultores familiares.

Praticar algum tipo de exercício físico ou esporte foi experimentado por alguns produtores do Bonfim quando eram crianças e frequentavam a escola. $\mathrm{Na}$ vida adulta, praticar exercícios físicos voluntários não faz parte da cosmologia dos agricultores locais. Excetua-se a caminhada que, por ter sido o meio de transporte mais usado no bairro por muitos anos, parece ser bem aceita pela população como uma opção de exercício. Até a década de 1990, não havia transporte coletivo no Bonfim e carros particulares eram raros. Para os moradores chegarem ao centro comercial tinham que caminhar cerca de sete quilômetros. Atualmente, a frequência dos ônibus é baixa e o serviço é precário, mas, de certa forma, facilita a locomoção dos moradores, reduzindo a assiduidade das caminhadas enquanto transporte.

\section{Considerações finais}

Não ter tempo fora do trabalho é característica marcante do cotidiano das famílias agricultoras do Bonfim. A margem de tempo de não trabalho era mais alargada quando a produção rural ainda não havia se modificado, mas, atualmente, a intensificação da agricultura na região parece ter reduzido essa margem ao extremo. Devido à acentuada insegurança econômica, o trabalho no Bonfim parece estar acima de qualquer outra atividade. Busca-se poupar tempo não com o intuito de alargar a margem de descanso ou de não trabalho, mas sim para poder trabalhar mais.

Como exposto nas seções anteriores, são muitos os fatores que interferem na prática alimentar e de atividade física no Bonfim. O tempo de trabalho parece ser um aspecto-chave que permeia outros fatores e, consequentemente, pode influenciar o estado nutricional da população. Para maximizar o tempo de trabalho e as vendas, os agricultores buscam maneiras de reduzir o tempo gasto com todas as atividades de não trabalho, incluindo comer e descansar. As famílias não plantam para autoconsumo, comprando alimentos industrializados e tentando minimizar o tempo gasto no preparo das refeições.
Não está sendo desconsiderada aqui a pertinência de outros possíveis determinantes da obesidade, tais como fatores hormonais e genéticos. Porém, enfatiza-se que, no Bonfim, a dinâmica trabalho-dieta parece representar papel relevante acerca do desgaste de morbidade da população, ou seja, da falta de equilíbrio entre processos extenuantes e aqueles de reposição, resultando em maior vulnerabilidade da coletividade em relação à ocorrência de problemas de saúde (LAURELL; NORIEGA, 1989). A respeito da obesidade no Bonfim, o desgaste acomete particularmente as mulheres, pois a redução da intensidade de suas atividades ocupacionais não foi acompanhada por mudanças na dieta. Essa apresenta composição semelhante para homens e mulheres, com predomínio de alimentos de alto valor calórico. A intensa atividade física da maioria dos homens parece equilibrar-se com a energia oriunda da dieta, protegendo-os contra obesidade.

Como intervenção contra a obesidade, modificar a forma de cultivar e reduzir a carga de trabalho não são, em curto prazo, opções possíveis na visão dos agricultores. Logo, seria necessário pensar estratégias junto com a comunidade, visando modificar a composição da dieta e/ou estimular a prática de atividade física voluntária. Este estudo observou que a comunidade percebe a obesidade como um problema, e que parte das mulheres tem buscado alternativas individuais para o emagrecimento. Cabe indagar: quais soluções coletivas a comunidade sugere como viáveis? Na visão da comunidade, por que as mulheres apresentam maior frequência de obesidade que os homens? Em longo prazo, seria interessante estimular, na associação de produtores local, discussões sobre possíveis caminhos que pudessem beneficiar as condições de trabalho e saúde da população.

Também não há como fugir da discussão sobre cultivo para autoconsumo e agricultura ecológica (livre de agrotóxicos), que parecem estar beneficiando aspectos de saúde e nutrição em outras comunidades agrícolas no país (RIGON et al., 2006). Por meio da motivação e de ideais ambientais de um filho de 26 anos, recentemente uma família do Bonfim iniciou, em paralelo à olericultura, uma (e até o momento a única) produção orgânica no bairro. A produção ainda é incipiente e apresenta problemas técnicos por estar relativamente próxima de lavouras convencionais. Contudo, segundo o jovem agricultor, a produção é usada para autoconsumo, além de, em parte, já estar sendo comprada por alguns citadinos locais, o que cobre seus gastos com sementes, permitindo a continuidade do cultivo.

Por ser um estudo de caso, não é esperado que os resultados observados no Bonfim possam ser generalizados para a diversidade de grupos de agricultores no Brasil. Todavia, importantes aspec- 
tos socioculturais locais que influenciam a obesidade podem auxiliar a compreensão da situação de saúde e nutrição de outros contextos agrícolas com características semelhantes ao Bonfim. Este estudo não somente mostrou que a obesidade pode acometer populações agricultoras, mas também que esta apresenta uma rede de determinantes que exige pesquisas de profundidade para ser avalia- da. Portanto, esta análise advoga a necessidade de estudar a obesidade integrando abordagens epidemiológicas e socioantropológicas. Quando se deixar de avaliar os determinantes da obesidade apenas superficialmente, poder-se-á identificar possíveis limitações, bem como portas de entrada para o desenvolvimento de ações de intervenção localmente relevantes.

\section{Agradecimentos}

A autora agradece ao Dr. Eduardo Stotz pelas ricas discussões sobre os argumentos deste artigo e à Dra. Andrea Wiley e ao Dr. James Trostle por auxiliarem na análise do material etnográfico. Agradecimentos também à comunidade do Bonfim, pois foi a colaboração de todos os moradores que possibilitou a realização deste estudo.

\section{Referências}

ANJOS, L. A. Obesidade e saúde pública. Rio de Janeiro: Fiocruz, 2006.

ASSOCIAÇÃO DE PRODUTORES E MORADORES DO BONFIM et al. A comunidade do Bonfim ameaçada pelo Decreto-Lei nº 90.023/1984. Petrópolis: APMB, 2009.

BARDIN L. Análise de Conteúdo. Lisboa: Edições 70, 1995.

BATISTA-FILHO, M.; RISSIN, A. A transição nutricional no Brasil: tendências regionais e temporais. Cadernos de Saúde Pública, Rio de Janeiro, v. 19, Suppl. 1, p. 181-191, 2003.

BOUCHARD, C. Current understanding of the etiology of obesity: genetic and nongenetic factors. American Journal of Clinical Nutrition, v. 53, Suppl., p. 1561-1565, 1991.

BRANDÃO, C. R. Plantar, colher e comer: um estudo sobre o campesinato goiano. Rio de Janeiro: Edições Graal, 1981.

BRESLOW, L. Commentary: On "public health aspects of weight control". International Journal of Epidemiology, v. 35, n. 1, p. 12-14, 2006.

CAMPANHOLA, C.; VALARINI, P. J. A agricultura orgânica e seu potencial para o pequeno agricultor. Cadernos de Ciência \& Tecnologia, Brasília, v. 18, n. 3, p. 69-101, set./dez. 2001.

CANDIDO, A. Os parceiros do Rio Bonito: estudo sobre o caipira paulista e a transformação dos seus meios de vida. 8. ed. São Paulo: Editora 34, 1997.

CARDOSO-OLIVEIRA, R. O trabalho do antropólogo: olhar, ouvir, escrever. In: _. . O trabalho do antropólogo. 2. ed. São Paulo; Brasília: Unesp; Paralelo 15, 2000. p. 17-35.

CARNEIRO, M. J. Ruralidade: novas identidades em construção. Estudos Sociedade e Agricultura, Rio de Janeiro, n. 11, p. 53-75, out. 1998.

. De produtor a consumidor: mudanças sociais e hábitos alimentares. In: NEVES, D. P. (Ed.). Processos de constituição e reprodução do campesinato no Brasil. São Paulo; Brasília: Unesp; Nead, 2009. p. 151-172.

CARNEIRO, M. J.; TEIXEIRA, V. L. Pluriatividade, novas ruralidades e identidades sociais. In: CAMPANHOLA, C.; SILVA, J. (Ed.). O novo rural brasileiro: novas ruralidades e urbanização. Brasília: Embrapa Informação Tecnológica, 2004. p. 15-37.

CONTRERAS, J. Patrimônio e globalização: o caso das culturas alimentares. In: CANESQUI, A. M.; GARCIA, R. W. D. (Ed.). Antropologia e nutrição: um diálogo possível. Rio de Janeiro: Fiocruz, 2005. p. 129-145.

\section{COORDENAÇÃO GERAL DA POLÍTICA DE} ALIMENTAÇAO E NUTRIÇÃO. Diagnóstico de saúde e nutrição da população do campo: levantamento de dados e proposta de ação. Brasília, DF: Ministério da Saúde, 2004.

FARIA, N. M. X. et al. Processo de produção rural e saúdena serra gaúcha: um estudo descritivo. Cadernos de Saúde Pública, Rio de Janeiro, v. 16, n. 1, p. 115-128, 2000.

FONSECA, M. F. A. C. et al. Características, estratégias, gargalos, limites e desafios dos circuitos curtos de comercialização de produtos orgânicos no Rio de Janeiro: as feiras. Revista Brasileira de Agroecologia, Cruz Alta, v. 4, n. 2, p. 2599-2602, 2009.

GARCIA, R. W. D. Representações sociais da alimentação e saúde e suas repercussões no comportamento alimentar. Physis, Rio de Janeiro, v. 7, p. 51-68, 1997.

\section{INSTITUTO BRASILEIRO DE GEOGRAFIA E} ESTATÍSTICA. Pesquisa de informações básicas municipais. Perfil dos municípios brasileiros: cultura, 2006. Rio de Janeiro: IBGE, 2007.

. Pesquisa de orçamentos familiares 20082009. Antropometria e estado nutricional de crianças, adolescentes e adultos no Brasil. Rio de Janeiro: IBGE, 2010a. 
. Pesquisa de orçamentos familiares 2008-2009.

Avaliação nutricional da disponibilidade domiciliar de alimentos no Brasil. Rio de Janeiro: IBGE, 2010b.

. IBGE Cidades. Disponível em: < http://www.ibge. gov.br/cidadesat/topwindow.htm?1>. Acesso em: 8 maio 2012. [base de dados online].

INTERNATIONAL OBESITY TASKFORCE. Obesity prevalence worldwide. Disponível em: < http://www. iaso.org/iotf/obesity>. Acesso em: 8 maio 2012. [base de dados online].

ITURRA, R. Trabalho de campo e observação participante em antropologia. In: SILVA, A. S.; PINTO, J. M. (Org.). Metodologia das Ciências Sociais. Porto: Edições Afrontamento, 1986. p. 32-43.

LAURELL, A. C.; NORIEGA, M. Processo de produção e saúde: trabalho e desgaste operário. São Paulo: Hucitec, 1989.

LOURENÇO, A. E. P. O Bonfim na balança: um estudo sobre ruralidade e saúde por meio da análise do estado nutricional, das práticas alimentares e da agricultura num bairro de Petrópolis, Rio de Janeiro. 2010. 202 f. Tese (Doutorado em Saúde Pública)-Escola Nacional de Saúde Pública, Fundação Oswaldo Cruz, Rio de Janeiro, 2010.

. The meaning of "rural" in rural health: a review and case study from Brazil. Global Public Health, v. 7, n. 1, p. 1-13, 2012.

MENASCHE, R.; SCHMITZ, L. C. Agriculturas de origem alemã, trabalho e vida: saberes e práticas em mudança em uma comunidade rural gaúcha. In: MENASCHE, R. (Ed.). Agricultura familiar à mesa: saberes e práticas da alimentação no Vale do Taquari. Porto Alegre: UFRGS, 2007. p. 78-99.

MINAYO, M. C. S. et al. Possibilidades e dificuldades nas relações entre ciências sociais e epidemiologia. Ciência $\mathcal{\sigma}$ Saúde Coletiva, Rio de Janeiro, v. 8, n. 1, p. 97-107, 2003.

MINTZ, S. W. Comida e antropologia: uma breve revisão. Revista Brasileira de Ciências Sociais, São Paulo, v. 16, n. 47, p. 31-41, 2001.

MOURA, M. M. Camponeses. 2. ed. São Paulo: Ática, 1988.

NAVARRO, Z. Desenvolvimento rural no Brasil: os limites do passado e os caminhos do futuro. Estudos Avançados, São Paulo, v. 15, p. 43, 2001.

ORMOND, J. G. P. et al. Agricultura orgânica: quando o passado é futuro. BNDES Setorial, Rio de Janeiro, n. 15, p. 3-34, março 2002.

PAULINO, S. M. As cidades e as serras. Espaço e identidades sociais na construção da ruralidade. In: MOREIRA, R. J. (Ed.). Identidades sociais: ruralidades no Brasil comtemporâneo. Rio de Janeiro: DP\&A 2005. p 255-274.

PEÑA, M.; BACALLAO, J. Obesity and poverty: a new public health challenge. Washington, DC: PAHO, 2000. (Scientific Publication, 576).
PERES, F; MOREIRA, J. C. Saúde e ambiente em sua relação com o consumo de agrotóxicos em pólo agrícola do Estado do Rio de Janeiro, Brasil. Cadernos de Saúde Pública, Rio de Janeiro, v. 23, Suppl. 4, p. S612-S621, 2007.

PERES, F.; ROZEMBERG, B.; LUCCA, S. R. Percepção de riscos no trabalho rural em uma região agrícola do Estado do Rio de Janeiro: agrotóxicos, saúde e ambiente. Cadernos de Saúde Pública, Rio de Janeiro, v. 21, n. 6, p. 1836-1844, nov./dez. 2005.

POLLAN, M. In defense of food. New York: Penguin, 2008.

POPKIN, B. M. The nutrition transition and obesity in the developing world. Journal of Nutrition, v. 131, n. 3, p. 871-873, mar. 2001.

RIGON, S. D. A. et al. A alimentação como forma de mediação da relação sociedade natureza: um estudo de caso sobre a agricultura ecológica e o auto-consumo em Turvo - PR. In: ENCONTRO DA ASSOCIAÇÃO NACIONAL DE PÓS-GRADUAÇÃO E PESQUISA EM AMBIENTE E SOCIEDADE, 3., 2006, Brasília. Anais... Brasília: ANPPAS, 2006. Disponível em: < http://www. anppas.org.br/encontro_anual/encontro3/arquivos/ TA284-04032006-140823.PDF > . Acesso em: 15 maio 2012.

SAMPAIO, M. F. A. et al. (In)segurança alimentar: experiência de grupos focais com populações rurais do Estado de São Paulo. Segurança Alimentar e Nutricional, Campinas, v. 13, n. 1, p. 64-77, 2006.

SHELL, E. R. The hungry gene: the inside story of the obesity industry. New York: Grove Press, 2002.

SOARES, W.; ALMEIDA, R. M. V. R.; MORO, S. Trabalho rural e fatores de risco associados ao regime de uso de agrotóxicos em Minas Gerais, Brasil. Cadernos de Saúde Pública, Rio de Janeiro, v. 19, n. 4, p. 1117-1127, 2003.

TROSTLE, J. A. Epidemiology and culture. Cambridge: Cambridge University Press, 2005.

ULIJASZEK, S. J.; LOFINK, H. Obesity in biocultural perspective. Annual Review of Anthropology, v. 35, p. 337-360, out. 2006.

VELÁSQUEZ-MELÉNDEZ, G. et al. Prevalence of metabolic syndrome in a rural area of Brazil. São Paulo Medical Journal, São Paulo, v. 125, n. 3, p. 155162, 2007.

WAGNER, S. A.; MARQUES, F. C.; MENASCHE, R. Agricultura familiar à mesa. In: MENASCHE, R. (Ed.). Agricultura Familiar à mesa: saberes e práticas da alimentação no Vale do Taquari. Porto Alegre: Editora da UFRGS, 2007.

WORLD HEALTH ORGANIZATION. The use and interpretation of antropometry: report of a WHO expert committee. Geneva: WHO, 1995.

. Obesity: preventing and managing the global epidemic. Geneva: WHO, 2000.

. The world health report 2002: reducing risks, promoting healthy life. Geneva: WHO, 2002. 